\title{
Distal semimembranosus muscle-tendon-unit review: morphology, accurate terminology, and clinical relevance
}

\author{
B. Benninger ${ }^{1}, 2,3,4,5,6,7,8$, T. Delamarter ${ }^{1}$ \\ ${ }^{1}$ Department of Medical Anatomical Sciences, Western University of Health Sciences, COMP-Northwest, \\ Lebanon, United States \\ 2Department of Neuromuscular Medicine, Western University of Health Sciences, COMP-Northwest, Lebanon, \\ United States \\ ${ }^{3}$ Department of Family Practice, Western University of Health Sciences, COMP-Northwest, Lebanon, United States \\ ${ }^{4}$ Samaritan Health Services Orthopaedics, Residency Faculty, Corvallis, United States \\ 5Samaritan Health Services General Surgery, Residency Faculty, Corvallis, United States \\ ${ }^{6}$ Department of Oral Maxillofacial Surgery, Oregon Health and Science University, Portland, United States \\ ${ }^{7}$ Department of Surgery, Oregon Health and Science University, Portland, United States \\ ${ }^{8}$ Department of Orthopaedics and Rehabilitation, Oregon Health and Science University, Portland, United States
}

[Received 1 March 2012; Accepted 30 April 2012]

Background: Our knowledge of the stability of the posteromedial knee is evolving. The distal semimembranosus is an important posteromedial stabilizer of the knee. Current anatomical texts and atlases do not accurately detail the distal insertion. Journal literature commonly mentions multiple distal insertions, one of which contributes to the oblique popliteal ligament. The purpose of this study was to review the literature, current morphology, terminology, and clinical relevance of the distal semimembranosus muscle-tendon-unit (SMTU), and suggest alternative nomenclature.

Materials and methods: A literature search was conducted on anatomical and clinical texts, atlases, journals, and websites to analyse the distal morphology of the semimembranosus muscle. Deep dissections were performed on $31 \mathrm{em}$ balmed cadavers, 56 knees in total (27 right and 29 left), identifying the distal semimembranosus tendon morphology.

Results: The literature search revealed significantly inconsistent morphology of the distal SMTU. Cadaver dissection revealed a consistent trifurcation with three dominant expansions. Cadaver dissection also revealed an oblique popliteal tendon/expansion, indigenous to the SMTU, not a ligament.

Conclusions: This study provides evidence of a consistent morphology and suggests a more precise nomenclature of the distal SMTU, which includes renaming the oblique popliteal ligament as the oblique popliteal tendon/expansion. (Folia Morphol 2013; 72, 1: 1-9)

Key words: semimembranosus, posteromedial knee, oblique popliteal ligament, distal semimembranosus tendon

\section{INTRODUCTION}

Posteromedial knee injuries are very common and their specific diagnosis, treatment, and prognosis are dependent on detailed knowledge of the anatomy and the ability to communicate clinically consistent standardised terminology. The distal semi- 
membranosus muscle-tendon-unit (SMTU) reinforces the posterior aspect of the knee from medial to lateral via its multiple expansions. Appreciating the expansions and the clinically relevant structures that are associated with each expansion will enable the health care provider to recognise the clinical significance that the semimembranosus has in the posteromedial stability of the knee. The objective of this study was to review the literature regarding the morphology, terminology, and clinical relevance of the distal SMTU and conduct an observational analysis using cadaveric dissection to clarify its morphology and suggest an alternative, standardised nomenclature.

Historic anatomical texts first proposed that the distal SMTU has multiple fibrous expansions [15, 43]. Recently, multiple research studies published in specialty journals have confirmed this and have revealed specific morphologies of the distal attachments of these expansions. However, the majority of current anatomical texts and atlases, except Standring [38] and Miller et al. [28], fail to accurately detail the distal SMTU. Rather they describe or illustrate a single insertion on the posteromedial aspect of the medial condyle of the tibia $[1,4,5,7,8,10-14,19,29,32$, $36,37,39]$. Despite multiple arborising branches of the distal SMTU, the terminology is inconsistent and confusing regardless of the specialty area of interest.

All texts, atlases, and specialty journals refer to the oblique popliteal ligament when discussing the distal semimembranosus insertion. Furthermore, though the majority of the texts and journal articles describe the distal semimembranosus tendon contributing to the oblique popliteal ligament (OPL) [1-3, 5-9, 12-18, 21-23, 25, 27-31, 33-38, 40, 43-45] few have hypothesised that this ligament is indigenous to the semimembranosus tendon; therefore, none have formally recognised this structure as a tendon itself. This study's proposed standardised nomenclature change of the distal SMTU includes the renaming of the OPL as the oblique popliteal tendon.

\section{MATERIALS AND METHODS}

A literature search was conducted on anatomical texts and atlases, orthopaedic texts, websites, and specialty journals (orthopaedic and radiological), regarding the distal SMTU. Deep dissections were performed on 31 embalmed cadavers (17 male, 14 female, age: 55-89, average: 79.6 years), 56 knees in total (27 right and 29 left). Exclusion criteria were amputation, knee replacement, or any gross damage to the knee joint. A skin incision was made in the anterior and posterior compartments of the knee starting $20 \mathrm{~cm}$ superior to the knee joint and extending $20 \mathrm{~cm}$ distal to the knee joint. Skin and fascia were reflected away from the midline until the tissue met the opposite incision. The distal semimembranosus tendon was identified superiorly. Both heads of the gastrocnemius were reflected at their superior attachments to fully expose the distal SMTU and the OPL. The contents of the popliteal fossa were carefully removed to preserve and expose the complete morphology of the SMTU. The distal aspect of the medial collateral ligament was reflected in order to expose the posteromedial aspect of the SMTU. Once the SMTU was identified superior to the joint line, it was dissected distally to analyse its morphology. The patterns of the SMTU were recorded. The most distal bony insertion of the semimembranosus was then reflected medial to lateral to observe whether or not the OPL was indigenous to the SMTU.

\section{RESULTS}

The literature search revealed two historical texts (prior to 1980, Essentials of human anatomy, $6^{\text {th }}$ Ed. and Anatomy for surgeons, Vol. 3: The back and limbs) that described multiple expansions of the distal SMTU $[15,43]$. Essentials of human anatomy, $6^{\text {th }}$ Ed. states: "The tendon of insertion of the semimembranosus ends mainly in the horizontal groove on the posteromedial aspect of the medial condyle of the tibia. Fibrous expansions of the tendon reach the lateral condyle of the femur (oblique popliteal ligament of the knee joint), the fascia of the popliteus muscle, and the tibial collateral ligament" [15]. Anatomy for surgeons, Vol. 3: The back and limbs states: "It (semimembranosus) becomes entirely tendinous behind the medial condyle of the femur, the tendon being rather short but heavy and inserting into the back of the medial tibial condyle. The straight part of the tendon attaches to the medial meniscus as it crosses that, and hence can help move the meniscus posteriorly. As it goes to its insertion it gives off an expansion that runs anteriorly to attach to the tibia deep to the tibial collateral ligament, another that runs obliquely upward and laterally across the posterior aspect of the knee joint, reinforcing and largely forming the oblique popliteal ligament, and still another that joins that fascia over the posterior surface of the popliteal muscle" [43].

Contemporary anatomical texts and atlases all describe or depict single distal attachment morphology of the distal SMTU $[1,4,5,7,8,10-14,19,29,32,36$, 37,39 ] except the $40^{\text {th }}$ Ed. of Gray's anatomy [38], which refers to five distal expansions, and the Surgical atlas of sports medicine [28], which depicts the inferior arm, 
anterior arm, capsular arm, direct arm, and oblique popliteal ligament. Specifically, Gray's $40^{\text {th }}$ Ed. states, "the tendon divides at the level of the knee into five components. The main one is attached to a tubercle (sometimes called the tuberculum tendinis) on the posterior aspect of the medial tibial condyle. The others are: a series of slips to the medial margin of the tibia, immediately behind the medial collateral ligament; a thin fibrous expansion to the fascia over popliteus; a cord-like tendon to the inferior lip and adjacent part of the groove on the back of the medial tibial condyle, deep to the medial collateral ligament; and a strong expansion which passes obliquely upwards to the femoral intercondylar line and lateral femoral condyle and forms much of the oblique popliteal ligament of the knee joint." All orthopaedic and radiologic journal articles referred to at least three fibrous attachments: the anterior arm, direct arm, and $\operatorname{OPL}[2,3,6,9,10,16-18$, $20-25,27,30,31,33-35,38,40-42,44,45]$. However, these studies were inconsistent with regard to the other fibrous expansions. They referred to $4[18,42]$, $5[6,27,35,45], 6[2,21,22]$, or $8[25,40]$ total expansions of the distal SMTU (Tables 1, 2).

The chronological account of the descriptions of the distal SMTU in orthopaedic and radiologic journal articles begins in 1948 and has continued to the present day. In 1948, Cave and Porteous [6] noted that there were five distal slips including the OPL. Cave and Porteous [6] described these slips as "short, stout, strong tendinous slips, descending in the line of the main insertion tendon and firmly attached to a prominent squarish tubercle on the posterolateral aspect of the medial tibial condyle, an expanded, thin superficial tendon, obscuring the deep lying first component and proceeding infero-medially to an insertion upon the medial margin of the tibia immediately behind the medial ligament of the knee joint, a thin aponeurotic expansion covering $\mathrm{m}$. popliteus and gaining an indirect attachment to the soleal (popliteal) line, a thick funicular, recurrent tendon passing infero-anteriorly, deep to the medial ligament of the knee joint, to gain attachment to the inferior lip and neighbourhood of the groove for semimembranosus on the medial tibial condyle, a variable number of irregularly disposed fasciculi, collectively constituting the oblique popliteal ligament and arising from the deep aspect of the main tendon of insertion" [6].

In 1961, Kaplan [20] indicated the complex nature of the semimembranosus insertion as dividing into several parts as it passes over the posterior half of the medial condyle and articular line of the knee joint. "One branch forming the direct insertion continues the course of the tendon and inserts directly and firmly into a tubercle (infraglenoid tubercle) found on the posterior face of the medial tuberosity of the tibia below the articular line and nearer the lateral end of this tuberosity. The tendon is continued distally and forms a wide aponeurotic fibrous expansion that fuses into the fascia of the popliteus and the periosteum of the medial part of the tibia posterior to the tibial insertion of the medial collateral ligament. Above the infraglenoid tubercle, the tendon of the semimembranosus is intimately attached to the posterior part of the capsule of the joint and also to the medial meniscus. The author found this insertion to be constantly present and responsible for posterior displacement of the medial meniscus in contractions of the semimembranosus. At this point the semimembranosus sends up oblique fibres that blend into the posterior capsule of the knee joint and are known as the posterior oblique ligament of the semimembranosus. These fibres contribute to tension of the capsule in flexion. Another insertion of the semimembranosus comes off at the articular line and forms a tendon-like structure anterior to the direct insertion. It crosses the articular line and enters a groove below the articular surface parallel to it on the posteromedial aspect. This tendinous insertion runs toward the anterior part of the medial collateral ligament and becomes fixed just behind the anterior part of the medial collateral ligament" [20].

In 1976, Hughston et al. [17] stated: "The tibial arm of the semimembranosus tendon has several branches including the fibrous covering which spreads out over the popliteus muscle". Following this, in 1979, Warren and Marshal [42] described the SMTU as having two main insertions and a tendon sheath. Specifically, "Most of the semimembranosus tendon inserts in bone through the direct insertion at the posteromedial corner of the tibia just below the joint line. A more anterior insertion, which is an extension of the direct insertion, proceeds around the medial side of the tibia just below the joint line. This anterior insertion lies deep to the superficial medial ligament and layer II and distal to the tibial margin of the capsule. It sends fibrous extensions upward and downward into layer II. The most clearly defined of these fibre tracts are the ones that extend directly upward over the medial condyle and across the back of the knee to the lateral condyle, forming the oblique popliteal ligament." A third, smaller extension: "runs distally to insert on the tibia posterior to the inferior oblique portion of the superficial medial ligament and to blend with the oblique fibres of that ligament to a varying degree. The division between 


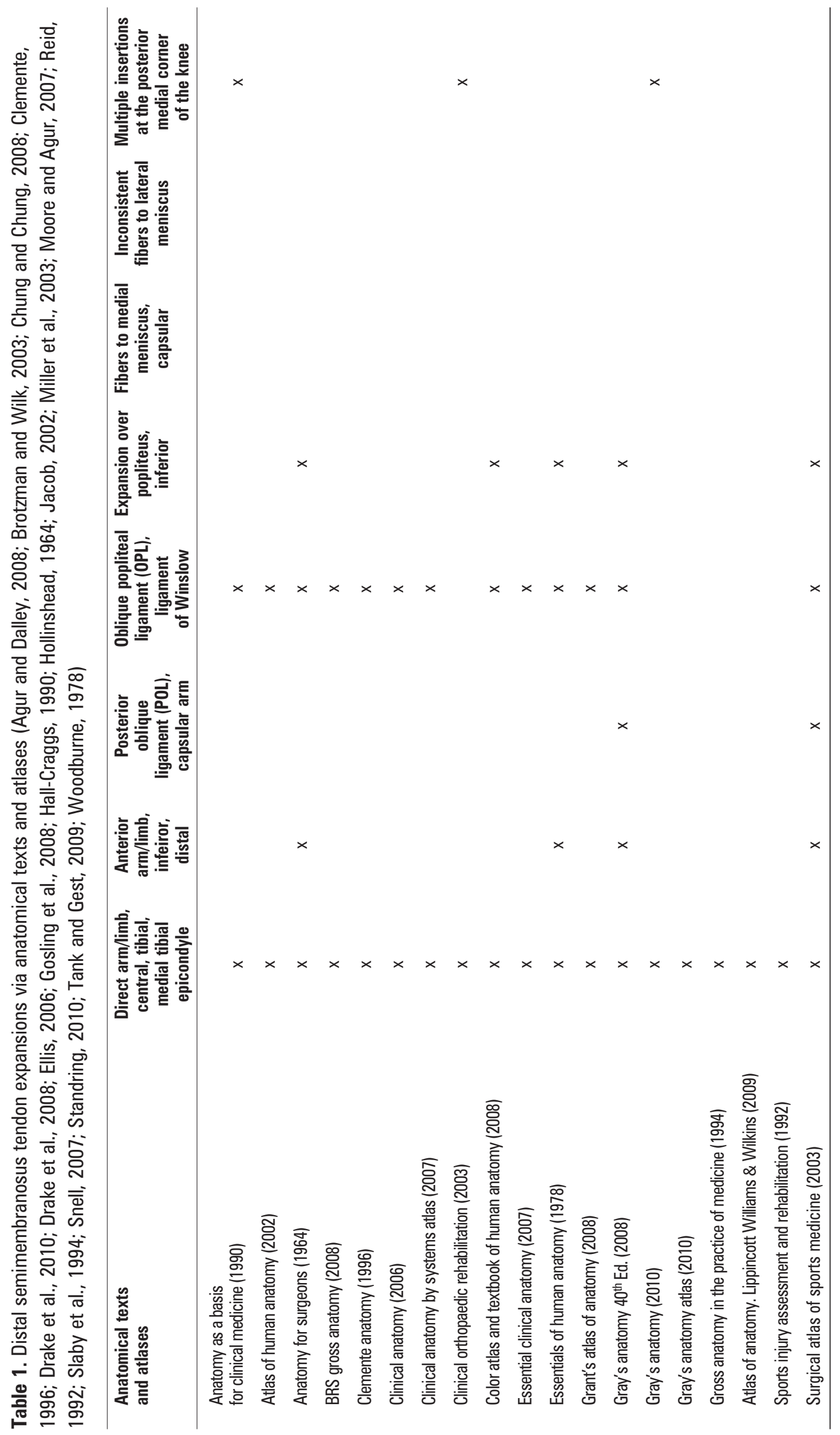




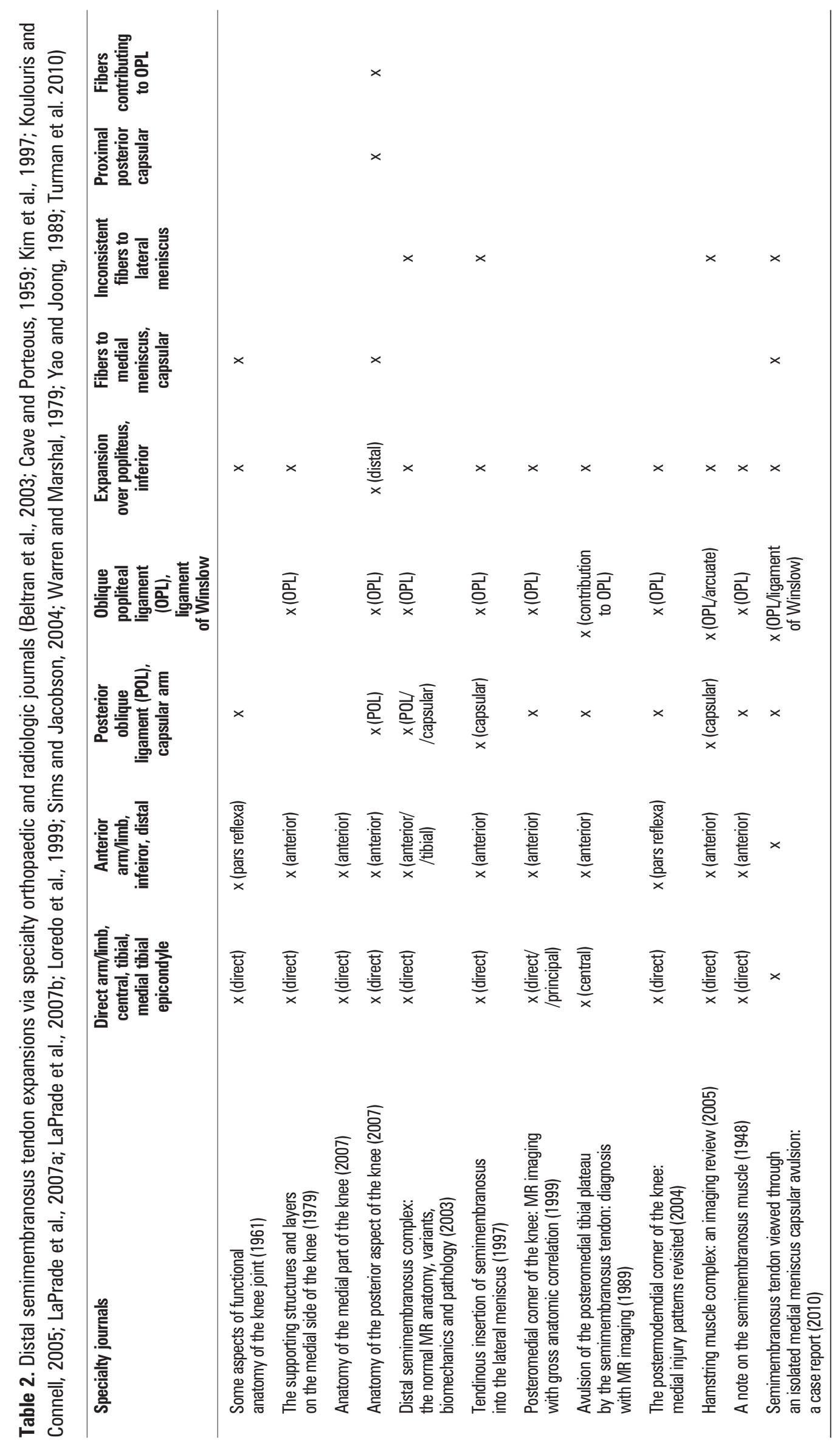


the tendon fibres (going directly to bone) and the fibres of the sheath (splaying out into the posteromedial part of the capsule) is usually clear. The tendon itself, however, may divide and distribute a few of its fibres to the posteromedial part of the capsule and to the oblique popliteal ligament".

In 1989, Yao and Joong [45] stated that there were "five distal expansions of the semimembranosus tendon". "Central tendon insertion, attachments to the deep capsule and the posterior horn of the medial meniscus, anterior limb inserting deep to the medial collateral ligament, distal fibrous expansion over the popliteus muscle, lateral contribution to the oblique popliteal ligament" [45].

In 1997, Kim et al. [21] divided the distal SMTU into five segments: "capsular, direct, anterior and inferior branches, and the oblique popliteal ligament," and added a sixth "tendinous insertion found in 16/ /37 (43.2\%) knees. The sixth tendinous fibre bundle was found to insert at the lateral meniscus". In 1999, Loredo et al. [27] concluded that there are "five arms of insertions, one being a principle attachment consisting of a series of slips of tendon". The principal or direct attachment was to the "tibial tubercle on the posterior aspect of the medial tibial condyle (just below the joint line)". The other slips were "anteriorly just beneath the superficial MCL; a third arm, derived mainly from the tendon sheath, blends with the posteromedial capsule; a fourth contributes substantially to the oblique popliteal ligament which extends over the posterior surface of the joint capsule; the fifth arm blends distally with the superficial MCL" [27].

In 2003, Beltran and Matityahu [2] explained the normal anatomy of the SMTU quite similarly to Kim et al. [21] "The distal semimembranosus tendon divides into five tendinous branches or arms at approximately the level of the joint line: the anterior or tibial arm, the direct arm, the inferior or popliteal arm, the capsular arm, the oblique popliteal ligament" [27]. This article further describes the expansions as follows: "The anterior or tibial arm, also known as the reflected arm, extends anteriorly passing under the posterior oblique ligament and inserts in the medial aspect of the proximal tibia under the tibial collateral ligament. The direct arm also has an anterior course, deep to the anterior arm, and it attaches in the posterior medial aspect of the tibia. The inferior or popliteal arm extends more distally than the anterior and the direct arms. It passes under the distal tibial segments of the posterior oblique ligament and the tibial collateral ligament, inserting just above the tibial attachment of the tibial collateral ligament. The cap- sular arm is contiguous with the posterior oblique ligament... and continuous with the OPL posteriorly. The OPL is a thin, broad lateral extension of the semimembranosus tendon that covers and blends with the posterior medial capsule and extends beyond the midline of the joint to intertwine its fibres with the arcuate ligament from the lateral posterior aspect of the knee. Additionally, two other tendinous extensions have been described: a distal attachment of the inferior or popliteal arm into the aponeurosis of the popliteus muscle, and an inconstant attachment to the posterior horn of the lateral meniscus" [27].

In 2004, Sims and Jacobson [35] described the posteromedial corner of the knee including five expansions of the SMTU as follows: "The pars reflexa, passing anteriorly beneath the tibial collateral the tibial collateral ligament and inserting directly on the tibia, the direct posteromedial tibial insertion, the oblique popliteal ligament insertion, the expansion to the POL, the popliteus aponeurosis expansion".

Again, in 2005, Koularis and Connel [23] described five tendinous arms or expansions to the medial tibial condyle. Three to the medial tibial condyle: "anterior, direct, and inferior arms". "The first three arms are closely related to the tibial collateral ligament, coursing deep to it". Also this article includes the "posterior oblique ligament (capsular arm), posterior joint capsule and arcuate ligament (oblique popliteal ligament)" and "slips to lateral meniscus in slightly less than one half of the population. Small slips of the semimembranosus tendon insert onto the posterior horn of the lateral meniscus" [23].

In 2006, Wymenga et al. [44] depicted the SMTU via pictures of fresh frozen cadaver tissue having five insertions: "the direct arm, posterior extension, capsular extension, tibial posterior extension, and inferior extension semimembranosus tendon sheath".

The most comprehensive description of the SMTU was published in 2007 by LaParade et al. [24, 25]. This article stated that there are: "Eight consistent posterior attachments of the semimembranosus muscle distal to the main common tendon at the knee. A direct arm, an attachment of the semimembranosus muscle distal to the main common tendon, a lateral tendinous expansion of the main common tendon that contributed to the oblique popliteal ligament, and an attachment to the coronary ligament of the medial meniscus, the oblique popliteal ligament, a proximal posterior capsular arm, a distal tibial expansion, an anterior arm, and the components of the posterior oblique ligament" [25]. 
Finally, in 2010, Turman et al. [40] referenced the previous paper published by LaParade et al. [25] and stated that the morphology of the distal SMTU has eight distal attachments.

Specifically with regard to the OPL, the following journal articles noted that the distal semimembranosus tendon forms the OPL. Cave noted the OPL as "a variable number of irregularly disposed fasciculi, collectively constituting the oblique popliteal ligament and arising from the deep aspect of the main tendon of insertion" [6]. Last [26] stated, "posteriorly the joint (knee) is also reinforced; an expansion from the tendon of insertion of semimembranosus extends upwards and laterally across the posterior part of the true capsule. This is the oblique posterior ligament of Winslow". Kaplan [20] writes, "The semimembranosus sends up oblique fibres that blend into the posterior capsule of the knee joint and are known as the posterior oblique ligament of the semimembranosus". Hughston and Eilers [18] depict the medial-posterior aspect of the right knee showing the OPL, which "originates from the capsular arm of the semimembranosus, which sends supporting fibres to the posterior oblique ligament". Warren and Marshal [42] state, "The most clearly defined of these fibre tracts are the ones that extend directly upward over the medial condyle and across the back of the knee to the lateral condyle, forming the oblique popliteal ligament". De Maeeseneer et al. [9] explain the formation of the OPL this way: "Along the posterior aspect of the knee, this structure (the POL) receives fibres from the semimembranosus tendon and synovial sheath. It envelops the posterior aspect of the femoral condyle, and in this area it is termed the oblique popliteal ligament". Recondo et al. [31] state "The oblique popliteal ligament joins the recurrent fascicle of the semimembranosus tendon, which reinforces the capsule". Beltran and Matityahu [2] states "the OPL is a thin, broad lateral extension of the semimembranosus tendon that covers and blends with the posterior medial capsule and extends beyond the midline of the joint to intertwine its fibres with the arcuate ligament from the lateral posterior aspect of the knee".

Embalmed cadaver dissection revealed a trifurcation of the distal SMTU at the posterior aspect of the medial femoral condyle in each of the 56 dissected knees. The trifurcation was analysed from proximal to distal. The first identified expansion coursed in a superior oblique direction to attach into the lateral aspect of the joint capsule directly posterior to the lateral femoral condyle. The second identified expansion of the trifurcation had an anterior course. It provided fibres into the medial meniscus and the medial collateral ligament, and terminated into the anteroinferior aspect of the medial tibial condyle. The third and terminal identified expansion of the trifurcation took an inferior course to the posterior inferior aspect of the medial tibial condyle, and was consistently more inferior than the anterior limb. This limb also provided fibres to the fascia of the popliteus muscle (Figs. 1A, B). Further analysis of the first expansion of the SMTU that coursed in a superior oblique manner required the SMTU to be reflected from its terminal insertion in a medial to lateral direction. This demonstrated that this expansion, the alleged oblique popliteal ligament, was in fact indigenous to the semimembranosus tendon and free of bony origin in each of the 56 dissected knees (Fig. 2).

\section{DISCUSSION}

Hollinshead and Woodburne both described multiple expansions of the distal SMTU contributing fibres to the oblique popliteal ligament, fascia over the popliteus muscle, medial collateral ligament, and lateral condyle of the femur $[15,43]$. Subsequently, numerous studies have confirmed the multiple fibrous expansions of the distal SMTU and their importance in posterior and medial knee stabilisation. However, all but two contemporary anatomical texts and atlases $[28,38]$ continue to refer to or depict a single distal attachment. With regard to the OPL, Woodburne [43] states that it is formed from the fibres of the distal semimembranosus tendon. All other anatomical texts and atlases that consider or depict the OPL state that the distal semimembranosus tendon contributes fibres to the OPL $[1-3,5-9,12-18,21-23,25,27-31,33-$ $-38,40,43-45]$. Our dissections revealed that the OPL originated solely from the distal semimembranosus tendon; therefore, it is in fact a tendon by the true sense of the definition. It is not a ligament inserting from bone to bone. We suggest this tendon be referred to as the oblique popliteal tendon (Fig. 1B).

Furthermore, though there is controversy regarding the less prominent expansions of this tendon, each study does agree on three expansions: an anterior arm, direct arm, and OPL. Despite this agreement, a common nomenclature for the distal SMTU does not exist. This study reveals a consistent trifurcation of the distal SMTU; therefore, the authors propose that the expansions of the trifurcation be named the oblique popliteal expansion (oblique popliteal tendon, not ligament), the anterior expansion, and the inferior expansion.

The order from proximal to distal regarding the limbs of the trifurcation is as follows. The oblique 

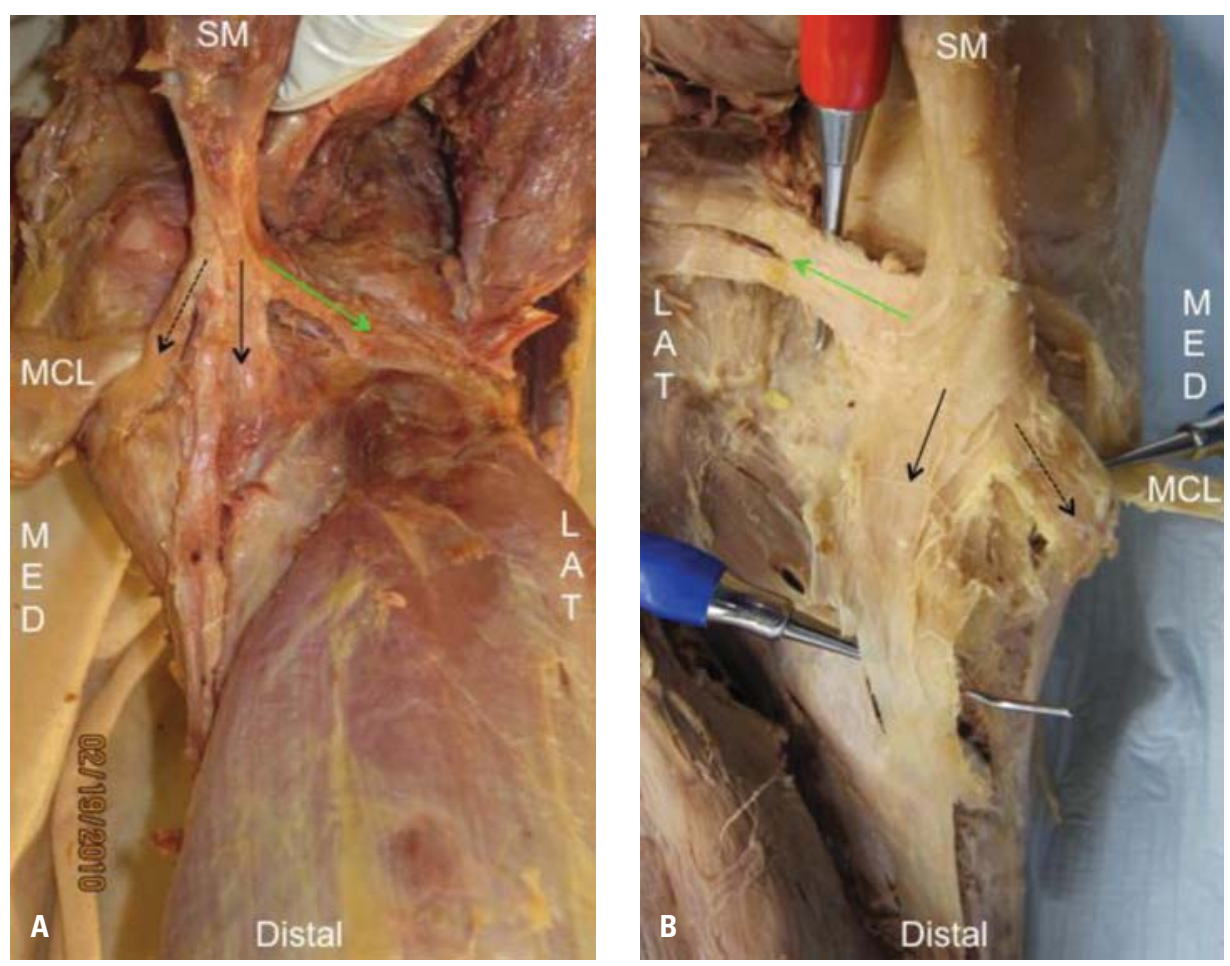

Figure 1. A, B. The distal semimembranosus muscle tendon unit; SM — semimembranosus muscle; $M C L$ - medial collateral ligament. Oblique popliteal ligament (expansion);

popliteal limb is the most proximal and is so named because it runs in a superior oblique manner across the popliteal fossa with expansions inserting into the posterior capsule. Next, the anterior limb is so named because of its anterior orientation, and the fact that it sends off expansion fibres to anteromedial structures including the medial meniscus and the medial collateral ligament. Finally, the inferior limb is so named because of its inferior orientation, which also sends off expansion fibres inferiorly to the fascia of the popliteus muscle. It inserts at the posteroinferior aspect of the medial tibial condyle (Fig. 2).

The posterior aspect of the knee has been studied increasingly because of its clinical relevance. Surgeons, biomechanists, physical therapists, all health care providers dealing with the musculoskeletal system, and anatomists need to have a definitive and precise understanding of the morphology of the distal SMTU. This study revealed a consistent trifurcation with three distinct limbs. This enabled accurate anatomical terminology to be used by all clinical and educational health care providers. Furthermore, this study strongly proposes the change of terminology from OPL to tendon. This is clinically important because of the proprioception of a tendon vs. a ligament. This may sug-

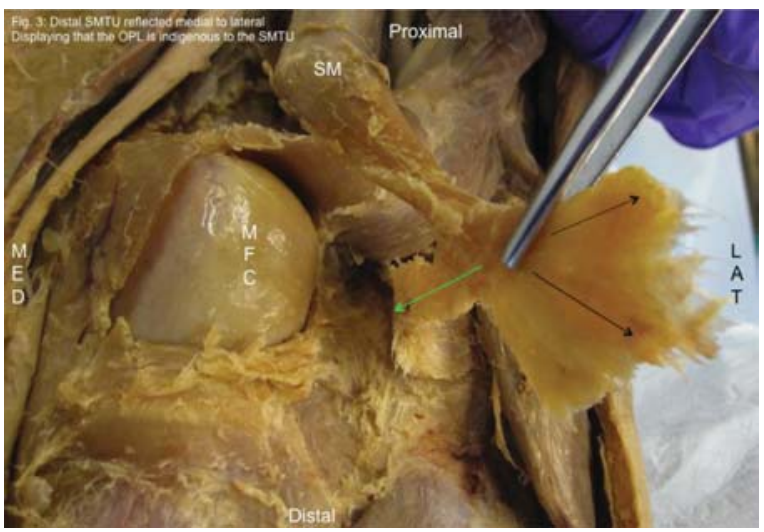

Figure 2. The distal semimembranosus muscle-tendon-unit reflected at its most distal attachment demonstrating that the oblique popliteal ligament is indigenous to this tendon; SM semimembranosus muscle; MFC — medial femoral condyle; $\longrightarrow$ Oblique popliteal ligament (expansion);

- Anterior expansion; $\longrightarrow$ Direct expansion.

gest a greater role by the distal semimembranosus tendon in posterior knee stability.

\section{ACKNOWLEDGEMENTS}

The authors would like to thank B. Davidson for manuscript support and Dr. B. Borman for data support and collegialism. 
The authors are grateful to all the donor-cadaverpatients whose gift enabled this study to be conducted in The McDaniel Clinical Anatomy Research Lab.

\section{REFERENCES}

1. Agur AMR, Dalley MF (2008) Grant's atlas of anatomy. 12 Ed. Lippincott Williams \& Wilkins, Baltimore, MD.

2. Beltran J, Matityahu A (2003) The distal semimembranosus complex: normal MR anatomy, variants, biomechanics, and pathology. Skeletal Radiol, 32: 435-445.

3. Brantigan OC, Voshell AF (1941) The mechanics of the ligaments of the knee Joint. J Bone Joint Surg, 23: 44-66.

4. Brotzman SB, Wilk KF (2003) Clinical orthopaedic rehabiliation. Elsevier, Philadelphia, PA.

5. Brukner P, Kahn K (2002) Clinical sports medicine. McGraw-Hill.

6. Cave A, Porteous CJ (1959) A note of the semimembranosus muscle. Ann R Coll Surg Engl, 24: 251-256.

7. Chung KW, Chunch HM (2008) Gross anatomy. 6 Ed. Lippincott Williams \& Wilkins, Baltimore.

8. Clemente CD (1996) Clemente anatomy. Lippincott Williams \& Wilkins, Baltimore, MD.

9. De Maessneer M, Van Roy F, Lenchik L, Barbaix E, De Ridder F, Osteaux M (2000) Three layers of the medial capsular and supporting structures of the knee: MR imaging-anatomic correlation. Radiographics, 20: S83-S89.

10. Drake RL, Vogl AW (2008) Gray's atlas of anatomy. Elsevier/Churchill Livingstone, Philadelphia, PA.

11. Drake RL, Vogl AW, Mitchell AWM (2010) Gray's anatomy for students. 2 Ed. Churchill Livingstone, Philadelphia, PA.

12. Ellis H (2006) Clinical anatomy. Wiley-Blackwell, Chichester, West Sussex.

13. Gosling JA, Harris PF (2008) Color atlas and textbook of human anatomy. Mosby Elsevier, Philadelphia, PA.

14. Hall-Craggs E (1990) Anatomy as a basis for clinical medicine. Urban \& Schwanzerberg, Baltimore, MD.

15. Hollinshead WH (1961) Anatomy for surgeons. Vol. 3. The back and limbs. Hoeber-Harper, New York.

16. Hughston J (1994) The importance of the posterior oblique ligament in repairs of acute tears of the medial ligaments in knees with and without rupture of the anterior cruciate ligament. J Bone Joint Surg, 77: 969.

17. Hughston J, Andres JR, Cross MJ (1976) Classification of knee ligament instabilities. Part 1. J Bone Joint Surg, 58: 159-172.

18. Hughston J, Eilers A (1973) The role of the posterior oblique ligament in repairs of acute medial (collateral) ligament tears of the knee. J Bone Joint Surg, 55: 923-940.

19. Jacob S (2002) Atlas of human anatomy. Churchill Livingstone, Philadelphia, PA.

20. Kaplan E (1961) Some aspects of functional anatomy of the human knee joint. Clinical Orthopedics, 23: 18-29.

21. Kim YC, Yoo WK, Chung IH, Seo JS, Tanaka S (1997) Tendinous insertion of the semimembranosus muscle the lateral meniscus. Surg Radiol Anat, 19: 365-369.

22. Koularis G, Connel D (2003) Evaluation of the hamstring muscle complex following acute injury. Skeletal Radiol, 32: 582-589.

23. Koularis G, Connel D (2005) Hamstring muscle complex: an imaging review. Radiographics, 25: 571-586.

24. LaPrade RF, Engebretsen AH, Ly TV, Johansen S, Wentorf FA, Engebretsen $L$ (2007) The anatomy of the medial part of the knee. J Bone Joint Surg, 89: 2000-2010.
25. LaPrade RF, Morgan PM, Wentorf FA, Johansen S, Engebretsen $L$ (2007) The anatomy of the posterior aspect of the knee. J Bone Joint Surg, 89: 758-764.

26. Last R (1948) Some anatomical details of the knee joint. J Bone Joint Surg, 30: 683-688.

27. Loredo R, Hodler J, Pedowitz L, Yeh R, Trudell D, Resnicket D (1999) Posteromedial corner of the knee: MR imaging with gross anatomic correlation. Skeletal Radiol, 28: 305-311.

28. Miller MD, Howard RF (2003) Surgical atlas of sports medicine. Saunders, Philadelphia, PA.

29. Moore KL, Agur AMR (2007) Essential clinical anatomy. Lippincott Williams \& Wilkins, Baltimore, MD.

30. Munshi M, Pretterklieber ML, Kwak S, Antonio GE, Trudell DJ, Resnick D (2003) MR imaging, MR arthrography, and specimen correlation of the posterorlateral corner of the knee an anatomic study. Am J Roentgenol, 180: 1095-1101.

31. Recondo J, Salvador E, Villanua JA, Barrera MC, Gervas C, Alustiza JM (2000) Lateral stabilizing structures of the knee: functional anatomy and injuries assesed with MR imaging. Radiographics, 20: S91-S102.

32. Reid DC (2004) Sports injury assesment and rehabilitation. Churchill Livingstone, New York.

33. Robinson J, Sanchez-Ballester J, Bull AM, Thomas RDEW, Amis AA (2004) The posteromedial corner revisited. An anatomical description of the passive restraining structures of the medial aspect of the human knee. Br Editorial Society Bone Joint Surg, 86: 674-681.

34. Seebacher J, Inglis AE, Marshall JL, Warren RF (1982) The structures of the posterolateral aspect of the knee. J Bone Joint Surg, 64: 536-541.

35. Sims WF, Jacobson KE (2004) The posteromedial corner of the knee: medial-sided injury patterns revisited. Am J Sports Med, 32: 337-345.

36. Slaby FJ, McCune SK, Summers RW (1994) Gross anatomy in the practice of medicine. Lea \& Febiger, Malvern.

37. Snell RS (2007) Clinical anatomy by systems. Lippincott Williams \& Wilkins, Baltimore.

38. Standring S (2010) Grays anatomy: the anatomical basis of clinical practice. Elsevier, Spain.

39. Tank PW, Gest TR (2009) Atlas of anatomy. Lippincott Williams \& Wilkins, Baltimore.

40. Turman KA, Miller CD, Miller MD (2010) Semimembranosus tendon viewed through an isolated medial meniscus capsular avulsion: a case report. Knee Surg Sports Traumatol Arthrosc, 18: 760-762.

41. Ulrich K, Kurdwig WK, Witzel U (2002) Posterolateral aspect and stability of the knee joint: anatomy and function of the popliteus muscle tendon-unit: an anatomical and biomechanical study. Knee Surg Sports Traumatol Arthrosc, 10: 86-90.

42. Warren L, Marschal J (1979) The supporting structures and layers on the medial side of the knee: an anatomical analysis. J Bone Joint Surg, 61: 56-62.

43. Woodburne RT (1978) Essentials of human anatomy. University Press, New York.

44. Wymenga A, Kats J, Kooloos J, Hillen B (2006) Surgical anatomy of the medial collateral ligament and the posteromedial capsule of the knee. Knee Surg Sports Traumatol Arthrosc, 14: 229-234.

45. Yao L, Joong LK (1989) Avusion of the posteromedial tibial plateau by the semimembranosus tendon: Diagnosis with MR imaging. Radiology, 172: 513-514. 